\title{
Late Ophthalmologic Referral of Anisometropic Amblyopia: A Retrospective Study of Different Amblyopia Subtypes
}

\section{Referenciação Tardia da Ambliopia Anisometrópica: Estudo Retrospetivo dos Diferentes Subtipos de Ambliopia}

\author{
Maria João VIEIRA $\triangle^{1,2}$, Sandra Viegas GUIMARÃES $3,4,5$, Patrício COSTA ${ }^{3,4,6}$, Eduardo SILVA ${ }^{7,8,9}$ \\ Acta Med Port 2019 Mar;32(3):179-182 - https://doi.org/10.20344/amp.10623
}

\section{ABSTRACT}

Introduction: Amblyopia requires a timely diagnosis and treatment to attain maximum vision recovery. Specialty literature is lacking on how early amblyopia is referred. We aimed to understand if there are mean age differences at first referral for ophthalmologic tertiary center consultation among non-amblyopic and different types of amblyopia, in a context of lack of population screening.

Material and Methods: In this retrospective model, the sample corresponded to all children born in Braga Hospital during 1997 - 2012 (3 - 18 years-old), with an ophthalmologic consultation in 2014. Data was collected from the clinical records and children were divided in a non-amblyopic versus amblyopic group. The amblyopic group was subdivided in strabismic versus refractive (anisometropic/ bilateral).

Results: The sample had a total of 1665 participants, 1369 (82.2\%) without amblyopia and $296(17.8 \%)$ with amblyopia. Among amblyopia: $67.9 \%(n=201)$ refractive, $32.1 \%(n=95)$ strabismic. Within refractive amblyopia: $63.7 \%(n=128)$ anisometropic and $36.3 \%(n=73)$ bilateral. The mean age at first consultation was $6.24 \pm 3.90$ years-old: $6.39 \pm 3.98$ for non-amblyopic and $5.76 \pm 3.58$ for amblyopic. Among amblyopia subgroups, there were significant differences in mean age at first consultation $\left(F_{3,1250}=8.45 ; p<0.001\right.$; $\eta 2=0.020$ ). Strabismic and bilateral refractive amblyopia were referred earlier, when compared to non-amblyopia or anisometropic amblyopia $(p<0.05)$. Anisometropic amblyopia had the highest first consultation mean age: $6.92 \pm 3.57$ years-old.

Discussion: Without specific pre-school screening, children with amblyopia were referred to their first ophthalmologic evaluation significantly later than desired, especially anisometropic amblyopia, with a postschool mean age for first consultation.

Conclusion: Recognizing high-risk children is essential for earlier referral and helps minimize future visual handicap.

Keywords: Amblyopia/epidemiology; Anisometropia/epidemiology

\section{RESUMO}

Introdução: A ambliopia requer uma abordagem atempada para uma máxima recuperação visual. Não existe informação sobre a idade de referenciação da ambliopia. O presente artigo pretende perceber se há diferenças na idade média de referenciação para consulta terciária de Oftalmologia, entre não-amblíopes e amblíopes, num contexto sem rastreio implementado.

Material e Métodos: A amostra correspondeu a todas as crianças nascidas no Hospital de Braga entre 1997 - 2012 (3 - 18 anos de idade), com consulta de Oftalmologia em 2014. A informação foi recolhida pelos registos clínicos, tendo sido criado o grupo nãoamblíope e amblíope, dividido em estrábico e refrativo (anisometrópico/bilateral).

Resultados: A amostra contemplou 1665 participantes, 1369 (82,2\%) não-amblíopes e 296 (17,8\%) amblíopes. Dentro das ambliopias: $67,9 \%(n=201)$ refrativas e $32,1 \%(n=95)$ estrábicas. Nas ambliopias refrativas: $63,7 \%(n=128)$ anisometrópicas e $36,3 \%(n=73)$ bilaterais. A média de idades na primeira consulta foi de $6,24 \pm 3,90$ anos, 6,39 $\pm 3,98$ nos não-amblíopes e 5,76 $\pm 3,58$ nos amblíopes. Dentro dos subgrupos de ambliopia, existiram diferenças significativas na idade na primeira consulta $\left(F_{3,1250}=8,45 ; p<0,001 ; \eta 2=\right.$ $0,020)$. As ambliopias estrábicas e as refrativas bilaterais foram referenciadas mais cedo, quando comparadas com não-amblíopes ou ambliopias anisometrópicas $(p<0,05)$. A ambliopia anisometrópica teve a maior média de idade na primeira consulta: 6,92 $\pm 3,57$ anos de idade.

Discussão: Sem um rastreio pré-escolar específico, os amblíopes foram referenciados para a primeira observação oftalmológica significativamente mais tarde do que o desejado, especialmente a ambliopia anisometrópica, com uma idade pós-escolar de média para a primeira avaliação oftalmológica.

Conclusão: Identificar crianças de alto risco é essencial para uma referenciação precoce, ajudando a minimizar consequências visuais.

Palavras-chave: Ambliopia/epidemiologia; Anisometropia/epidemiologia

\section{INTRODUCTION}

One of the major causes of monocular blindness is amblyopia, being therefore regarded as a public health problem. ${ }^{1-3}$ Amblyopia is a neurodevelopmental vision disorder

caused by sensory deficits during the critical period of visual development, such as strabismus, high refractive errors or visual deprivation. ${ }^{4}$

\footnotetext{
1. School of Medicine. University of Minho. Braga. Portugal.

2. Department of Ophthalmology. Hospital de Santo André. Centro Hospitalar de Leiria. Leiria. Portugal.

3. Life and Health Sciences Research Institute. School of Medicine. University of Minho. Braga. Portugal.

4. ICVS/3Bs. PT Government Associate Laboratory. Braga/Guimarães. Portugal.

5. Department of Ophthalmology. Hospital de Braga. Braga. Portugal.

6. Clinical Academic Center-Braga. Braga. Portugal.

7. Centro Cirúrgico de Coimbra. Coimbra. Portugal.

8. IBILI. Faculty of Medicine. University of Coimbra. Coimbra. Portugal.

9. Department of Ophthalmology. Centro Hospitalar Lisboa Norte. Lisbon. Portugal.

$\triangle$ Autor correspondente: Maria João Vieira. vieiramjp@gmail.com

Recebido: 05 de abril de 2018 - Aceite: 23 de outubro de 2018 | Copyright @ Ordem dos Médicos 2019
} 
Treating amblyopia improves visual acuity, binocularity and decreases the likelihood of developing severe visual handicaps later in life. ${ }^{5}$ Despite these effects, ${ }^{6}$ maximum visual recovery declines after a non-consensual threshold age that can go up to 7 years of age..$^{-9}$ Prompt amblyopia detection is, therefore, mandatory. . $^{5,10-18}$

The latest USPFTS guidelines ${ }^{19}$ state that "studies directly evaluating the effectiveness of screening were limited and do not establish whether vision screening in preschool children is better than no screening".

Unfortunately, data is lacking on how amblyopia is treated and prevented, as well as when the first ophthalmologic appointment is made in Portugal. ${ }^{20}$

In this study we have characterized the age at first ophthalmologic evaluation in Braga Hospital (Portugal), prior to an amblyopia prevention project. ${ }^{21}$ in order to understand if different subtypes of functional amblyopia (versus nonamblyopic children) are referred in different ages. In sum, we addressed the question: Are there differences in the mean age at first ophthalmologic evaluation between nonamblyopic versus amblyopic children, as well as between functional amblyopia subtypes: refractive amblyopia versus strabismic amblyopia?

\section{MATERIAL AND METHODS}

We performed a retrospective study, reviewed and approved by the local ethics committee of the Braga Hospital. The sample corresponded to all children born in Braga Hospital during 1996 - 2011 (3 to 18 years-old in collection time), with an ophthalmologic consultation in 2014. Ophthalmologic information present in the electronic clinical database (Global Intelligence Technologies, Glintt ${ }^{\circledR}$ ) was collected for this study.

Amblyopia was diagnosed as previously described $\mathrm{in}^{22}$ and included registration of occlusive treatment in addition to strabismus or refractive error. In cases without occlusive treatment, the inclusion criteria for anisometropic amblyopia was: an interocular difference of $\geq 2$ lines in best-corrected visual acuity (BCVA) and an amblyogenic refractive error $(A R E)$ responsible for that difference. ${ }^{1,23}$ For bilateral refractive amblyopia, the criteria was: ARE present plus bilateral $B C V A<5 / 10$ in 3 or 4 -year-old subjects or ARE plus bilateral BCVA $<8 / 10$ in 5+ year-old subjects. ${ }^{21}$ Children who had unilateral and bilateral criteria where classified as bilateral amblyopia, as in Friedman et a/24 Strabismic amblyopia included combined strabismic plus refractive amblyopia. The diagnosis was reviewed by a trained ophthalmologist. Organic amblyopia cases were excluded. The age at first ophthalmologic consultation was also collected.
The Shapiro-Wilk test was used to test for normality, which was confirmed in all tested variables of the sample. Levene's test was used to evaluate variance homogeneity, having revealed heteroskedasticity of all tested variables of the sample. Therefore, the Welch's F test was used to compare amblyopia subgroups regarding mean age at first consultation, with multiple comparisons being done with the Games-Howell test. A one sample $t$ test was used to compare the age means in the first consultation and an optimal theoretical first evaluation age.

Statistical analyses were performed using the Statistical Package for the Social Sciences (IBM SPSS Statistics $22^{\circledR}$ ). Two-sided $p$-values $<0.05$ (95\% confidence interval) were considered statistically significant. Two different effect size measures were calculated: partial eta squared $\left(\eta_{p}^{2}\right)$ [small 0.01 , medium 0.06 , large 0.14 ] and Cohen's $d$ scores [small 0.2 , medium 0.5 , large 0.8$].^{25,26}$

\section{RESULTS}

The sample had a total of 1665 participants [832 female $(49.9 \%)$ ], with a mean age of $8.64 \pm 3.92$ years-old. Within the sample, there were 1369 subjects (82.2\%) without amblyopia and 296 subjects $(17.8 \%)$ with amblyopia. Among amblyopia cases, $67.9 \%(n=201)$ corresponded to the refractive subtype and $32.1 \%(n=95)$ to the strabismic subtype. Within refractive amblyopia: $63.7 \%(n=128)$ had anisometropic amblyopia and $36.3 \%(n=73)$ had bilateral refractive amblyopia.

The mean age at first consultation was $6.24 \pm 3.90$ years-old: $6.39 \pm 3.98$ in the non-amblyopia group and 5.76 \pm 3.58 in the amblyopia group. Mean age at first consultation had significant differences among the three amblyopia subgroups $(p<0.001 ; \eta 2=0.020)$ (Table1).

Strabismic and bilateral refractive amblyopia had a significantly lower age, when compared to non-amblyopia ( $p$ $=0.008$ and $p=0.002$, respectively) or to anisometropic amblyopia ( $p=0.003$ and $p=0.001$, respectively) (Table 2 and Fig. 1). Anisometropic amblyopia had the highest mean age at first consultation: $6.92 \pm 3.57$ years-old, with no significant differences when compared to non-amblyopia. (Fig. 1). Strabismic amblyopia had the lowest median and bilateral refractive amblyopia the lowest mean (Table 1), despite no statistically significant differences having been found between these two groups.

Significant differences were found in the mean age of amblyopia first consultation (5.76 \pm 3.58 years-old) and an optimal theoretical first evaluation age of: 3 years-old $\left(t_{281}=\right.$ $12.9, p<0.001, d=1.54)$, 4 years-old $\left(t_{281}=8.22, p<0.001\right.$, $d=0.98)$ and 5 years-old $\left(t_{281}=3.54, p<0.001, d=0.42\right)$.

Table 1 - Multiple pairwise comparisons: Games-Howell post-hoc test

\begin{tabular}{lcccc} 
& $\begin{array}{c}\text { Bilateral refractive } \\
\text { amblyopia }\end{array}$ & $\begin{array}{c}\text { Strabismic } \\
\text { amblyopia }\end{array}$ & No amblyopia & $\begin{array}{c}\text { Anisometropic } \\
\text { amblyopia }\end{array}$ \\
\hline No amblyopia & $1.73 ; \boldsymbol{p}=\mathbf{0 . 0 0 2}$ & $1.34 ; \boldsymbol{p}=\mathbf{0 . 0 0 8}$ & \\
\hline Anisometropic amblyopia & $2.26 ; \boldsymbol{p}=\mathbf{0 . 0 0 1}$ & $1.88 ; \boldsymbol{p}=\mathbf{0 . 0 0 3}$ & \\
\hline
\end{tabular}

Only statistically significant results were reported 


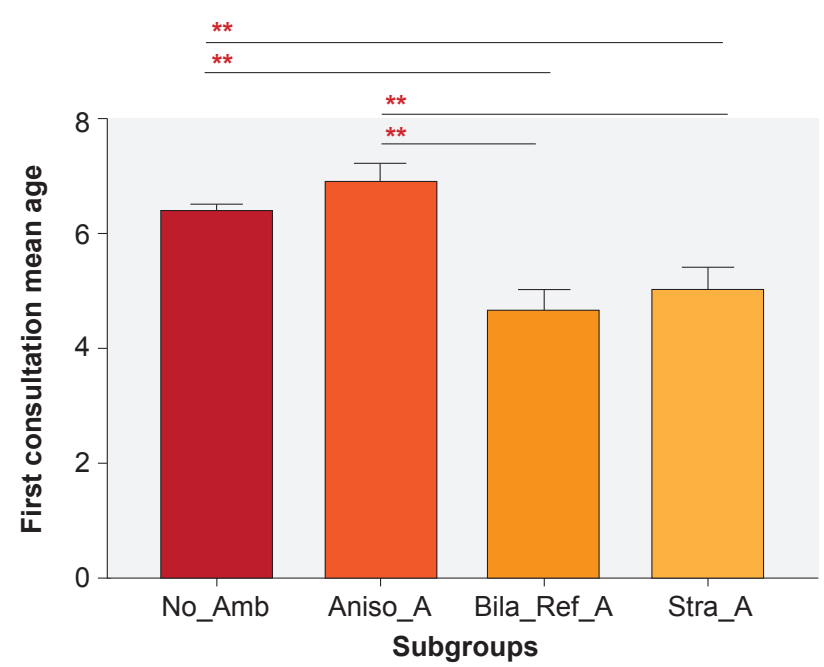

Figure 1 - First consultation mean age in the different amblyopia subgroups. First consultation mean age had significant differences among the amblyopia subgroups $(p<0.001 ; \eta 2=0.020)$ : strabismic and bilateral refractive amblyopia had statistically lower age, when compared to non-amblyopia $(p=0.008$ and $p=0.002$, respectively) or to anisometropic amblyopia $(p=0.003$ and $p=0.001$, respectively).

No_Amb: no amblyopia; Aniso_A: anisometropic amblyopia; Bila_Ref_A: bilateral refractive amblyopia; Stra_A: trabismic amblyopia. ${ }^{* *}: p<0.01$

\section{DISCUSSION}

Children with amblyopia were referred to their first ophthalmologic evaluation significantly later than desired, possibly explained by the lack of population-based screening.

Anisometropic amblyopia was referred later than all subgroups $(p<0.05)$, while strabismic and bilateral refractive amblyopia had the lowest mean age at first consultation. This is possibly due to the fact that anisometropic amblyopia conveys no signs of suspicion, while in strabismic and bilateral refractive amblyopic children belonging to high-risk groups, there is an objective evidence of squint in strabismus or difficulty in performing visual tasks in high bilateral ametropias that are easily seen by pediatricians, general practitioners or even by parents. ${ }^{27-29}$

Chua et $a^{27}$ and Groenewoud et $a^{\beta 0}$ also found that refractive amblyopia is detected later, between 3.3 and 4.5 years of age. However, they did not split refractive subtype in anisometropic and bilateral. Our study finds an even latter detection for refractive amblyopia and especially for anisometropic amblyopia, with a postschool mean age of 6.92 years-old for anisometropic amblyopia. Anisometropic amblyopia comprises almost 2/3 of refractive amblyopia cases, reinforcing its problematic later detection.

Our study considers bilateral plus unilateral refractive amblyopia as bilateral refractive amblyopia, since the clinical signs and symptoms are probably due to the bilateral aspect. This methodology leads to a higher bilateral refractive amblyopia prevalence than it was previously reported. ${ }^{1}$ Bilateral refractive amblyopia has the earliest referral of all subgroups: the mean age at first consultation is significantly lower than non-amblyopia or than anisometropic amblyopia. We speculate this could be also due to a possible positive family history of high degree refractive error that could lead to an early referral.

Amblyopia is almost 5 times more prevalent than expected $^{1,31,32}$ in the pediatric population of Braga Hospital, which is easily justified by the highly differentiated hospital population (tertiary center bias).

As a limitation of our study, age at first consultation was recorded in years: having collected the age in months would have brought more accuracy to our study, but this was not possible due to its retrospective nature and the lack of available information in medical records.

\section{CONCLUSION}

Refractive amblyopia is the major functional amblyopia subtype. The division of refractive amblyopia in bilateral refractive amblyopia and anisometropic amblyopia is the key and innovative point of this study, giving us a new insight on this complex pathology.

Without no population-based vision screening at the time of data collection, this late detection may consequently lead to amblyopia treatment after the age limit threshold (up to 7 years-old) and, possibly, an irreversible lower vision recovery.

In summary, anisometropic amblyopia screening by pediatricians or general practitioners is not as effective as strabismic or bilateral refractive amblyopia detection. It seems important to have an organized preschool vision

Table 2 - Statistical tests for mean age at first consultation among amblyopia subgroups

\begin{tabular}{|c|c|c|c|c|c|}
\hline & \multicolumn{4}{|c|}{ Central Tendency Measurements } & \multirow{2}{*}{$\begin{array}{l}\text { Welch } F \text { test } \\
p \text { value and } \\
\text { effect size }\end{array}$} \\
\hline & No amblyopia & $\begin{array}{c}\text { Anisometropic } \\
\text { ambylopia }\end{array}$ & $\begin{array}{c}\text { Bilateral refractive } \\
\text { amblyopia }\end{array}$ & $\begin{array}{l}\text { Strabismic } \\
\text { amblyopia }\end{array}$ & \\
\hline 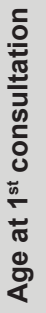 & $\begin{array}{l}n=1369 \\
M \pm S D=6.39 \pm 3.98 \\
M d n \pm I Q R=6 \pm 5(3-8)\end{array}$ & $\begin{array}{l}n=128 \\
M \pm S D=6.92 \pm 3.57 \\
M d n \pm I Q R=6 \pm 5(5-9)\end{array}$ & $\begin{array}{l}n=73 \\
M \pm S D=4.66 \pm 2.96 \\
M d n \pm I Q R=5 \pm 5(2-7)\end{array}$ & $\begin{array}{l}n=95 \\
M \pm S D=5.04 \pm 3.61 \\
M d n \pm I Q R=4 \pm 5(2-7)\end{array}$ & $\begin{array}{l}F_{(3,1250)}=8.45 \\
p<0.001 \\
\eta^{2}=0.020\end{array}$ \\
\hline
\end{tabular}

$\mathrm{n}$ : number of subjects; $\mathrm{M} \pm \mathrm{SD}$ : mean \pm standard deviation; $\mathrm{Mdn} \pm \mathrm{IQR}$ : median \pm interquartile range

$p$ : $p$ value, statistically significant when $p<0.05 ; n p^{2}$ : partial eta squared (small 0.01 , medium 0.06 , large 0.14 ) 
screening with refractive error detection and/or visual acuity measurement.

\section{PROTECTION OF HUMANS AND ANIMALS}

The authors declare that the procedures were followed according to the regulations established by the Clinical Research and Ethics Committee and to the Helsinki Declaration of the World Medical Association.

\section{DATA CONFIDENTIALITY}

The authors declare having followed the protocols in

\section{REFERENCES}

1. Wallace DK, Repka MX, Lee KA, Melia M, Christiansen SP, Morse CL, et al. Amblyopia preferred practice pattern(R). Ophthal. 2018;125:105-42.

2. Wong AM. New concepts concerning the neural mechanisms of amblyopia and their clinical implications. Can J Ophthalmol. 2012;47:399-409.

3. Buch $H$, Vinding $T$, La Cour M, Nielsen NV. The prevalence and causes of bilateral and unilateral blindness in an elderly urban Danish population. The Copenhagen City Eye Study. Acta Ophthalmol Scand. 2001;79:441-9.

4. Chua B, Mitchell P. Consequences of amblyopia on education, occupation, and long term vision loss. Br J Ophthalmol. 2004;88:111921.

5. Tarczy-Hornoch K, Cotter SA, Borchert M, McKean-Cowdin R, Lin J, Wen G, et al. Prevalence and causes of visual impairment in Asian and non-Hispanic white preschool children: Multi-ethnic Pediatric Eye Disease Study. Ophthalmology. 2013;120:1220-6.

6. Rutstein RP. Contemporary issues in amblyopia treatment. Optometry. 2005; $76: 570-8$

7. Williams C, Northstone K, Harrad RA, Sparrow JM, Harvey I. Amblyopia treatment outcomes after screening before or at age 3 years: follow up from randomised trial. BMJ. 2002;324:1549.

8. Williams C, Northstone K, Harrad RA, Sparrow JM, Harvey I. Amblyopia treatment outcomes after preschool screening $v$ school entry screening: observational data from a prospective cohort study. $\mathrm{Br} \mathrm{J}$ Ophthalmol. 2003;87:988-93.

9. Holmes JM, Lazar EL, Melia BM, Astle WF, Dagi LR, Donahue SP, et al. Effect of age on response to amblyopia treatment in children. Arch Ophthalmol. 2011;129:1451-7.

10. Donahue SP, Arthur B, Neely DE, Arnold RW, Silbert D, Ruben JB. Guidelines for automated preschool vision screening: a 10-year, evidence-based update. J AAPOS. 2013;17:4-8.

11. Forcina BD, Peterseim MM, Wilson ME, Cheeseman EW, Feldman S, Marzolf $\mathrm{AL}$, et al. Performance of the spot vision screener in children younger than 3 years of age. Am J Ophthalmol. 2017;178:79-83.

12. Koning HJ, Groenewoud JH, Lantau VK. Effectiveness of screening for amblyopia and other eye disorders in a prospective birth cohort study. J Med Screen. 2013;20:66-72.

13. Joish VN, Malone DC, Miller JM. A cost-benefit analysis of vision screening methods for preschoolers and school-age children. J AAPOS. 2003;7:283-90.

14. Solebo AL, Cumberland PM, Rahi JS. Whole-population vision screening in children aged 4-5 years to detect amblyopia. Lancet. 2015;385:230819.

15. Schmucker C, Grosselfinger R, Riemsma R. Effectiveness of screening preschool children for amblyopia: a systematic review. BMC Ophthalmol. 2009;9:3. use at their working center regarding patients' data publication.

\section{CONFLICTS OF INTEREST}

All authors report no conflict of interest.

\section{FUNDING SOURCES}

This research received no specific grant from any funding agency in the public, commercial, or not-for-profit sectors.

16. Lagreze WA. Vision screening in preschool children: do the data support universal screening? Dtsch Arztebl Int. 2010;107:495-9.

17. Hopkins S, Sampson GP, Hendicott P, Wood JM. Review of guidelines for children's vision screenings. Clin Exp Optom. 2013;96:443-9.

18. Cotter SA, Miller JM, Quinn GE. Vision screening for children 36 to 72 months: recommended practices. Opto Vision Sci. 2014; 92:6-16.

19. Jonas DA, Wallace IF, Feltner C, Vander Schaaf EB, Brown CL, Baker C. Vision screening in children aged 6 months to 5 years: a systematic review for the U.S. Preventive Services Task Force. JAMA. 2017;318:845-58

20. Lanca C, Serra H, Prista J. Strabismus, visual acuity, and uncorrected refractive error in portuguese children aged 6 to 11 years. Strabismus. 2014;22:115-9.

21. Guimaraes S, Fernandes T, Costa P, Silva E. Should tumbling E go out of date in amblyopia screening? Evidence from a population-based sample normative in children aged 3-4 years. Br J Ophthalmol. 2018;102:761-6.

22. Guimaraes S, Vieira M, Queiros T, Soares A, Costa P, Silva E. New pediatric risk factors for amblyopia: strabismic versus refractive. Eur $\mathrm{J}$ Ophthalmol. 2018;28:229-33.

23. American Academy of Ophthalmology. Preferred Practice Pattern ${ }^{\circledR}$ Guidelines: Amblyopia. San Francisco: AAO; 2012.

24. Friedman DS, Repka MX, Katz J. Prevalence of amblyopia and strabismus in white and African American children aged 6 through 71 months: The Baltimore Pediatric Eye Disease Study. Ophthalmology. 2009;116:2128-34.

25. Kotrlik JW, Williams HA. The incorporation of effect size in information technology, learning, and performance. Infor Tech, Lear and Perfor Jour. 2003;21:1-7.

26. Cohem J. Statistical power and analysis for the behavioral sciences. $2^{\text {nd }}$ ed. Hillsdale: Lawrence Erlbaum Associates; 1988.

27. Brian BE, Johnson K, Martin F. A retrospective review of the associations between amblyopia type, patient age, treatment compliance and referral patterns. Clin Exp Ophthalmol. 2004;32:175-9.

28. Membreno JH, Brown MM, Brown GC, Sharma S, Beauchamp GR. A cost-utility analysis of therapy for amblyopia. Ophthalmology. 2002;109:2265-71.

29. Group Tpedi. The clinical profile of moderate amblyopia in children younger than 7 years. Arch Ophthalmology. 2002;120:281-7.

30. Groenewoud JH, Tjiam AM, Lantau VK. Rotterdam amblyopia screening effectiveness study: detection and causes of amblyopia in a large birth cohort. Invest Ophthalmol Vis Sci. 2010;51:3476-84

31. Pai AS, Rose KA, Leone JF. Amblyopia prevalence and risk factors in Australian preschool children. Ophthalmology. 2012;119:138-44.

32. Hendler K, Mehravaran S, Lu X, Brown SI, Mondino BJ, Coleman AL. Refractive errors and amblyopia in the UCLA Preschool Vision Program; first year results. Am J Ophthalmology. 2016;172:80-6. 